\title{
Sparse network models reproduce experimentally observed spike timing jitter during inspiratory population rhythms in the pre-Bötzinger complex Michael S Carroll ${ }^{* 1}$ and Jan-Marino Ramirez ${ }^{2}$
}

\author{
Address: ${ }^{1}$ Committee on Computational Neuroscience, The University of Chicago, Chicago, IL 60637, USA and ${ }^{2}$ Department of Organismal \\ Biology and Anatomy, The University of Chicago, Chicago, IL 60637, USA \\ Email: Michael S Carroll* - msc@uchicago.edu \\ * Corresponding author
}

from Seventeenth Annual Computational Neuroscience Meeting: CNS*2008

Portland, OR, USA. 19-24 July 2008

Published: II July 2008

BMC Neuroscience 2008, 9(SuppI I):PI4 doi:I0.I I86/I47I-2202-9-SI-PI4

This abstract is available from: http://www.biomedcentral.com//47I-2202/9/SI/PI4

(C) 2008 Carroll and Ramirez; licensee BioMed Central Ltd.

Neurons within the pre-Bötzinger complex of the ventral respiratory group (VRG) in the medulla generate rhythmic network activity which has been shown to be essential for normal breathing in vivo. Furthermore, many physiological responses of this network are preserved in transverse medullary brain slice preparations, where bursts of population discharge are typically recorded with large, lowimpedance electrodes [1]. Recent analysis of multiunit extracellular recordings from this in vitro preparation has shown that the onset timing of spikes from the individual neurons that make up this rhythm is quite variable on a burst-by-burst basis. A conductance-based model [2] of this network with all-to-all connectivity fails to reproduce this variability, while a model with sparse (but proportionally stronger) synaptic coupling generates firing patterns with a higher fidelity to the experimental results (see Figure 1). Specifically, the mean variance of burst-triggered spike timing was $0.0218 \pm 0.0184$ (SD) for in vitro recordings, $0.0347 \pm 0.0267$ for sparsely connected network models, and $0.0004 \pm 0.0023$ for fully connected models. Continuing simulations will explore further relationships between parameters of network topology and spike timing variability. 


\section{Experiment}

A

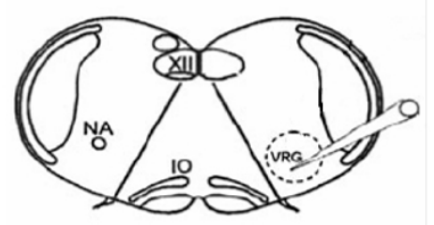

D

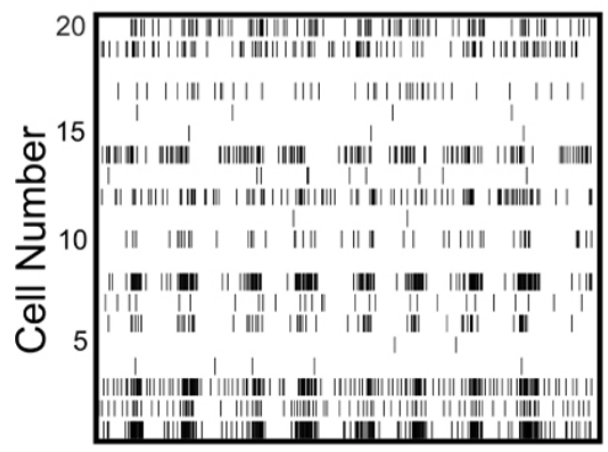

Model

B

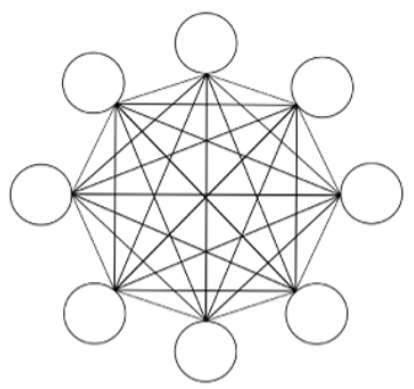

E

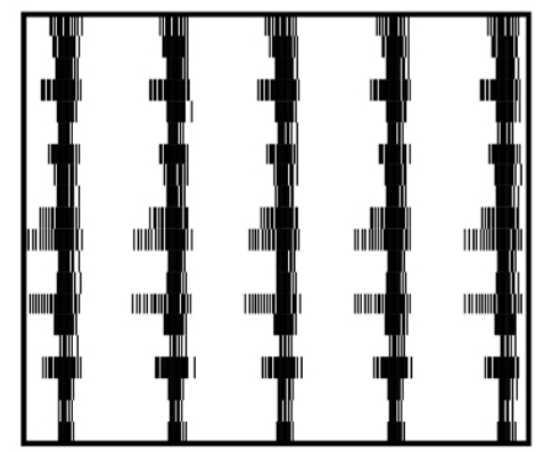

C

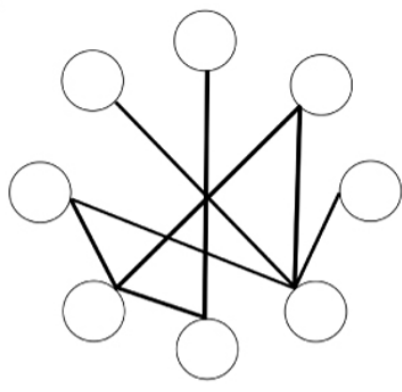

F

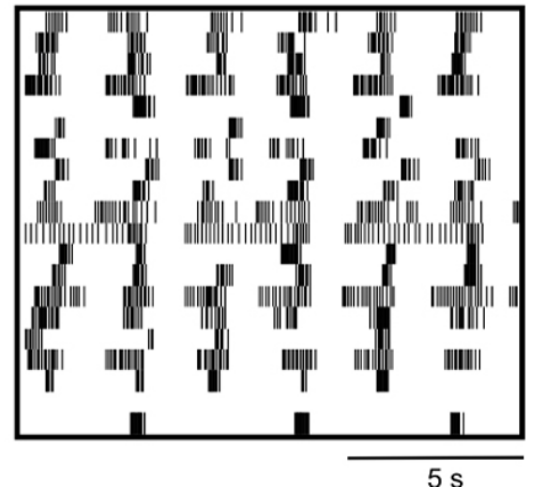

Figure I

In vitro and modeling results for networks with varying connectivity. Schematic of transverse slice preparation of the ventral lateral medulla (A) and connectivity profiles for fully (B) and sparsely connected (C) network models. Example spike time raster of individually identified neurons during normal population rhythms (D) show noticeable variability in burst onset timing. This variability is reproduced in sparsely connected network models (F) but not in fully connected networks (E). For simulation rasters a random selection of 20 of 300 simulated cells is shown.

\section{References}

I. Ramirez J-M, Tryba AK, Peña F: Respiratory rhythm generation: converging concepts from in vitro and in vivo approaches? Respir Physiol Neurobiol 2002, I 3 I (I-2):43-56.

2. Rybak IA, Shevtsova NA, Ptak K, McCrimmon DR: Intrinsic bursting activity in the pre-Botzinger complex: role of persistent sodium and potassium currents. Biol Cybern 2004, 90(I):59-74.

\begin{tabular}{|} 
Publish with Bio Med Central and every \\
scientist can read your work free of charge \\
"BioMed Central will be the most significant development for \\
disseminating the results of biomedical research in our lifetime. " \\
Sir Paul Nurse, Cancer Research UK \\
Your research papers will be: \\
• available free of charge to the entire biomedical community \\
• peer reviewed and published immediately upon acceptance \\
• cited in PubMed and archived on PubMed Central \\
• yours - you keep the copyright \\
Submit your manuscript here: \\
http://www.biomedcentral.com/info/publishing_adv.asp
\end{tabular}

